Check for updates

Cite this: RSC Adv., 2019, 9, 14247

Received 12th March 2019

Accepted 1st May 2019

DOI: $10.1039 / c 9 r a 01879 d$

rsc.li/rsc-advances

\section{Facile construction of magnetic core-shell covalent organic frameworks as efficient solid- phase extraction adsorbents for highly sensitive determination of sulfonamide residues against complex food sample matrices}

\begin{abstract}
Jing-Min Liu, (D) a Shi-Wen Lv, (D) a Xin-Yue Yuan, ${ }^{b}$ Hui-Lin Liu (DD b and Shuo Wang*ab
Integration of advanced sample pretreatment techniques, with the involvement of functional nano/micromaterials as adsorbents, is of great importance and value for food-safety precise inspection. For now, the major demands for functional adsorbents are ease of fabrication, fast adsorption and separation performance, low toxicity, robustness, and reusability. In the present work, core-shell structured magnetic covalent organic frameworks (COFs) that employed $\mathrm{Fe}_{3} \mathrm{O}_{4}$ microspheres as the magnetic core and TpBD COFs as the adsorption shell have been successfully constructed as efficient solid phase extraction (SPE) adsorbents for complex food sample analysis. In favor of the combination of magnetic separation and effective preconcentration, the proposed magnetic COF-SPE method gave a rapid detection performance of the simultaneous detection of ten sulfonamide residues as well as high sensitivity, with detection limits in the range of $0.28-1.45 \mu \mathrm{g} \mathrm{L}^{-1}$ under the optimized experimental conditions. The $\mathrm{Fe}_{3} \mathrm{O}_{4} \mathrm{QTpBD}$ core-shell adsorbents also demonstrated good stability, robust SPE preconcentration ability, excellent determination recovery, and good reusability. The applicability of the developed SPE method was well demonstrated by real sample analysis, with the recoveries ranging from $82-94 \%$. Through this example, it was believed that the new emerging porous nano/micro-materials, like COFs, metal-organic networks, or hybrid structures, would play more and more important roles as functional materials in food-safety inspection, especially for highly efficient determination of targets against complicated food sample matrices.
\end{abstract}

\section{Introduction}

Nowadays, food-borne pesticides and veterinary drug residues still hold significant threat to food-safety, the environment, and human health. Therein, sulfonamides, a typical group of antimicrobial veterinary drugs, have raised great attention for safety concerns, due to their illegal use and continual overdosing. ${ }^{1-4}$ This problem would get more and more serious while the withdrawal period of the hazards gets too short to allow effective clearance. As a result of extensive widespread usage of sulfonamides, rising concerns and significant attention have been placed on their potential human health risk, owing to their carcinogenic potency and possible role in the development of antibiotic resistance. ${ }^{5,6}$ In consideration of the continuous problem escalation, the maximum residue limit for sulfonamides in animal foods such as eggs, meat, and milk has been officially established by the European Union, China and several

${ }^{a}$ Tianjin Key Laboratory of Food Science and Health, School of Medicine, Nankai University, Tianjin 300071, China. E-mail: elisasw2002@aliyun.com

${ }^{b}$ Beijing Advanced Innovation Center for Food Nutrition and Human Health, Beijing Technology \& Business University (BTBU), Beijing, 100048, China other countries. ${ }^{7-10}$ Therefore, development of rapid, sensitive, and useful quantification methods for sulfonamides in food come to be of great importance and desire. ${ }^{11}$

Owing to the simple operation, good repeatability, and its being contaminant-free, solid phase extraction (SPE) is a wellacknowledged technique for sample pretreatment of food, environmental, and biological samples via enrichment of target substances at trace levels. ${ }^{12-16}$ Therein, employment of magnetic adsorbents into the SPE process produces the magnetic SPE technique, which is advantageous compared with traditional SPE in terms of simplicity, speed, and amount of adsorbent required. ${ }^{17-20}$ Magnetic SPE only needs one magnet to retrieve magnetic adsorbents post the enrichment process, avoiding the time-consuming centrifugation steps. Moreover, high back-pressure and adsorbent clogging problem hardly occur in magnetic SPE, ensuring good reproducibility and considerable extraction efficiency. ${ }^{21-24}$ Magnetic SPE is used in many fields, such as biological chemistry, analytical chemistry, and environmental protection. ${ }^{25-27}$ The core part of magnetic SPE is selection of the magnetic material with porous structure and functional groups as adsorbents.

Different from conventional porous materials especially metal-organic frameworks (MOFs), covalent organic frameworks 
(COFs), with the nature of carbonaceous polymeric materials, possess relative high chemical and structure stability, both in water and organic media. ${ }^{28-31}$ Born with well-defined nanopores and skeletons, COFs are composed with light-weight elements (C, $\mathrm{B}, \mathrm{H}, \mathrm{O}, \mathrm{N}$ ) and organized through dynamic covalent bonding, endowing unique features, such as pre-designable pore geometry, large surface area, excellent crystallinity, and high flexibility in surface modification and structural design. In particular, their large surface area and tunable porosity enable COFs to serve as a promising platform for adsorption, bioimaging, drug delivery, biosensing and theranostic applications. ${ }^{32-36}$

Herein, novel core-shell structured magnetic COFs, employing $\mathrm{Fe}_{3} \mathrm{O}_{4}$ microspheres as magnetic core and TpBD COFs as adsorption shell, have been successfully constructed as efficient solid phase extraction adsorbents for highly sensitive determination of sulfonamides residues. In favor of combination of magnetic separation and effective preconcentration, the proposed magnetic COF-SPE method gave rapid detection performance of simultaneous detection of ten sulfonamides residues as well as high sensitivity, with the detection limits in the range of $0.28-1.45 \mu \mathrm{g} \mathrm{L}^{-1}$ under the optimized experimental conditions. The $\mathrm{Fe}_{3} \mathrm{O}_{4} @ \mathrm{TpBD}$ core-shell adsorbents also demonstrated good stability, robust SPE preconcentration ability, excellent determination recovery, and good reusability. The applicability of the developed SPE method was well testified by real sample analysis, with the recoveries ranging from $82-94 \%$. This work demonstrates good compatibility of porous nano/ micro-structures with various food-borne hazardous substances, giving the possibility of highly efficient determination of targets against complicated food sample matrix (Fig. 1).

\section{Experimental section}

\subsection{Chemicals and materials}

All reagents used in this experiment were at least analytical grade. All the ultrapure water used in the experiment was obtained through Milli-Q (Millipore, Bradford, MA, USA). Ten sulfonamides: sulfamethoxazole (SMZ), sulfafurazole (SIZ), sulfamethizole (SMT), sulfadiazine (SD), sulfadimidine (SM2),

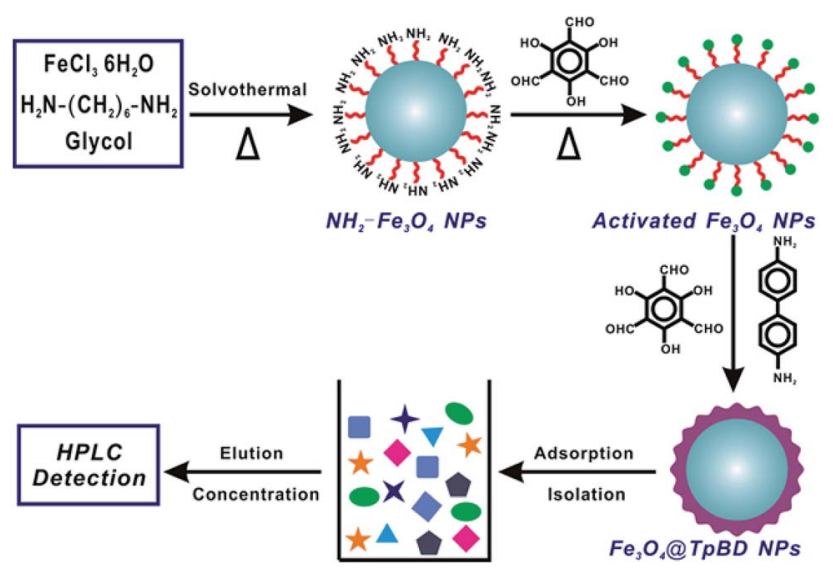

Fig. 1 Schematic illustration of magnetic core-shell covalent organic frameworks as efficient solid-phase extraction adsorbents for determination of sulfonamides residues. sulfametoxydiazine (SMD), sulfadoxine $\left(\mathrm{SDM}^{\prime}\right)$, sulfapyridine (SPD), sulfathiazole (ST), sulfamethoxypyridazine (SMP) were purchased from Sigma. 1,3,5-Triformylphloroglucinol (Tp), glycol, diglycolic anhydride (DA), 1,6-hexanediamine, benzidine (BD), and $\mathrm{FeCl}_{3} \cdot 6 \mathrm{H}_{2} \mathrm{O}$ were purchased from Aladdin (Shanghai, China). Ethanol, $N, N$-dimethylformamide (DMF), tetrahydrofuran (THF), mesitylene, and 1,4-dioxane were purchased from Concord Chemical Research Institute (Tianjin, China). $\mathrm{HNO}_{3}$ were obtained from Guangfu Fine Chemical Research Institute (Tianjin, China). All glassware should be soaked in aqua regia $\left(\mathrm{HCl}: \mathrm{HNO}_{3}=3: 1, \mathrm{v} / \mathrm{v}\right)$ for at least $24 \mathrm{~h}$ and cleaned with ultrapure water.

\subsection{Characterization and instrumentation}

The morphology and nano/micro-structure of the assynthesized adsorbents was characterized through the scanning electron microscopy (SEM, LEO 1530VP microscope, LEO, Germany) and high-resolution transmission electron micrograph (HRTEM, JEM-2100F field emission transmission electron microscope, JEOL, Japan). XRD patterns were acquired on a D/max-2500 diffractometer (Rigaku, Japan) equipped with $\mathrm{Cu}$ $\mathrm{K} \alpha$ radiation $(\lambda=1.5418 \AA)$. The surface area and porosity of the as-prepared adsorbents were tested by the nitrogen adsorptiondesorption analysis.

\subsection{Preparation of magnetic $\mathrm{Fe}_{3} \mathrm{O}_{4} @ \mathrm{TpBD}$}

The core-shell structured magnetic $\mathrm{Fe}_{3} \mathrm{O}_{4} @ \mathrm{TpBD}$ adsorbent was synthesized via covalent coating of TpBD COFs onto the surface of $\mathrm{Fe}_{3} \mathrm{O}_{4}$ magnetic microspheres.

Synthesis of amine-functionalized $\mathrm{Fe}_{3} \mathrm{O}_{4}$ microspheres. The magnetic $\mathrm{Fe}_{3} \mathrm{O}_{4}$ microspheres were synthesized according to the hydrothermal method. Typically, $1.0 \mathrm{~g}$ of $\mathrm{FeCl}_{3} \cdot 6 \mathrm{H}_{2} \mathrm{O}$ was dissolved in $30 \mathrm{~mL}$ of glycol, followed by addition of $2.0 \mathrm{~g}$ of anhydrous sodium acetate and $5 \mathrm{~mL}$ of 1,6-hexanediamine under stirring. Then vigorous stirring was applied on the mixture to give a transparent solution. Afterwards, the reaction liquid was gently transferred into a Teflon-lined autoclave, and the reaction was allowed for proceeding at $190^{\circ} \mathrm{C}$ for $6 \mathrm{~h}$ to give the amine-functionalized $\mathrm{Fe}_{3} \mathrm{O}_{4}$ microspheres. The obtained black microspheres were recovered and washed by ultrapure water and ethanol with the assistance of a magnet, dried under vacuum, and stored in dark.

Synthesis of $\mathrm{Fe}_{3} \mathrm{O}_{4} @ \mathbf{T p B D}$ microspheres. The aminefunctionalized $\mathrm{Fe}_{3} \mathrm{O}_{4}$ microspheres were firstly treated with Tp to facilitate the following COF coating, and the reaction was allowed to process at $50{ }^{\circ} \mathrm{C}$ for $1 \mathrm{~h}$ to obtain the surfaceactivated $\mathrm{Fe}_{3} \mathrm{O}_{4}$ microspheres.

To a $100 \mathrm{~mL}$ flask, $25 \mathrm{mg}$ of $\mathrm{Fe}_{3} \mathrm{O}_{4}$ microspheres, BD (0.45 $\mathrm{mmol})$, and $\mathrm{Tp}(0.30 \mathrm{mmol})$ were gently mixed with $20 \mathrm{~mL}$ of ethanol under stirring to give a homogenous solution at room temperature. Afterwards, the whole reaction vessel was treated with Ar atmosphere by continuous purging for $15 \mathrm{~min}$ to remove the $\mathrm{O}_{2}$. Then the reaction mixture was heated to $80{ }^{\circ} \mathrm{C}$ to reflux the mixed liquid in Ar atmosphere, and the heating was allowed to process for $3 \mathrm{~h}$ under vigorous stirring. The resultant suspension was retrieved with the assistance of a magnet and 
thoroughly washed with water and ethanol. Afterwards, the obtained $\mathrm{Fe}_{3} \mathrm{O}_{4}$ @TpBD microspheres were gave two-cycle of DMF washing under refluxing for another $2 \mathrm{~h}$ to remove the excessive Tp and $\mathrm{BD}$, and the DMF was exchanged by following ethanol washing, evacuated in vacuum at room temperature overnight to remove the ethanol. The dried materials were collected in the agate mortar to grind into powder and stored in dark.

\subsection{Magnetic $\mathrm{Fe}_{3} \mathrm{O}_{4} @ T$ TPD-based SPE assay}

In a typical SPE assay, $20 \mathrm{mg}$ of magnetic $\mathrm{Fe}_{3} \mathrm{O}_{4}$ @TpBD powder was mixed with $20 \mathrm{~mL}$ of standard or sample solutions in a $50 \mathrm{~mL}$ bottle, followed by shaking for $10 \mathrm{~min}$ at room temperature to ensure the complete interaction of analytes with SPE adsorbents. Afterwards, the $\mathrm{Fe}_{3} \mathrm{O}_{4} @ \mathrm{TpBD}$ microspheres were collected with an external magnet and the supernatant was removed. Then $5 \mathrm{~mL}$ of acetonitrile was introduced to desorb the analytes by gentle shaking for $2 \mathrm{~min}$. The obtained solution was purged with nitrogen to dry the eluate at room temperature, and re-dissolved in $200 \mu \mathrm{L}$ of methanol $(20 \mu \mathrm{L}$ for HPLC analysis).

\subsection{HPLC separation}

HPLC analysis was carried out on Shimadzu LC-10 system along with UV-detection $(270 \mathrm{~nm}$ for analyte measurement throughout the experiments). HPLC separation was realized via an Agilent XDB-C18 column (4.6 $\mathrm{mm} \times 250 \mathrm{~mm}, 5 \mu \mathrm{m})$ operated at $35{ }^{\circ} \mathrm{C}$ with an injection volume of $20 \mu \mathrm{L}$. The optimized mobile phase was composed with methanol and water $(22: 78$, $\mathrm{v} / \mathrm{v}, \mathrm{pH}=3.25$ ), delivered at a flow rate of $1 \mathrm{~mL} \mathrm{~min}^{-1}$.

\section{Results and discussion}

\subsection{Synthesis and characterization of magnetic $\mathrm{Fe}_{3} \mathrm{O}_{4} @ T$ TPD}

To grow TpBD COFs shell on the surface of magnetic $\mathrm{Fe}_{3} \mathrm{O}_{4}$ microspheres, a dense amine group layer was employed. The amine groups on magnetic $\mathrm{Fe}_{3} \mathrm{O}_{4}$ microspheres have the ability to combine with Tp via the covalent imine bond under a certain condition, so magnetic $\mathrm{Fe}_{3} \mathrm{O}_{4} @ \mathrm{TpBD}$ can be successfully synthesized. The XRD pattern of as-obtained $\mathrm{Fe}_{3} \mathrm{O}_{4} @ \mathrm{TpBD}$ was shown in Fig. 2A. It was observed that the reflection peaks in XRD pattern of $\mathrm{Fe}_{3} \mathrm{O}_{4} @$ $\mathrm{TpBD}$ matched well with the pure TpBD crystals, suggesting the existence of TpBD phase compositions in the composites. The diffraction peaks at $30.1^{\circ}(220), 35.5^{\circ}$ (311) and $43.2^{\circ}$ (400) were corresponding to the crystalline $\mathrm{Fe}_{3} \mathrm{O}_{4}$ (JCPDS PDF no. 65-3107), indicating the hybrid of TpBD had no remarkable impact on the crystal structure of the $\mathrm{Fe}_{3} \mathrm{O}_{4}$ microspheres. Nitrogen adsorption-desorption was carried out to determine the surface area, and the result revealed that $\mathrm{Fe}_{3} \mathrm{O}_{4} @ \mathrm{TpBD}$ possessed a large specific surface area of $356.4 \mathrm{~m}^{2}$ $\mathrm{g}^{-1}$ (Fig. 2B), much higher than that of bare $\mathrm{Fe}_{3} \mathrm{O}_{4}$ microspheres $\left(73.5 \mathrm{~m}^{2} \mathrm{~g}^{-1}\right)$ and slightly lower than pure TpBD COFs $\left(435 \mathrm{~m}^{2}\right.$ $\left.\mathrm{g}^{-1}\right)$. The TpBD shell coated onto the $\mathrm{Fe}_{3} \mathrm{O}_{4}$ core possessed the typical porous structure, with the similar pore size of $3.5 \mathrm{~nm}$ as pure TpBD $(3.6 \mathrm{~nm})$. The magnetic properties of $\mathrm{Fe}_{3} \mathrm{O}_{4}$ and
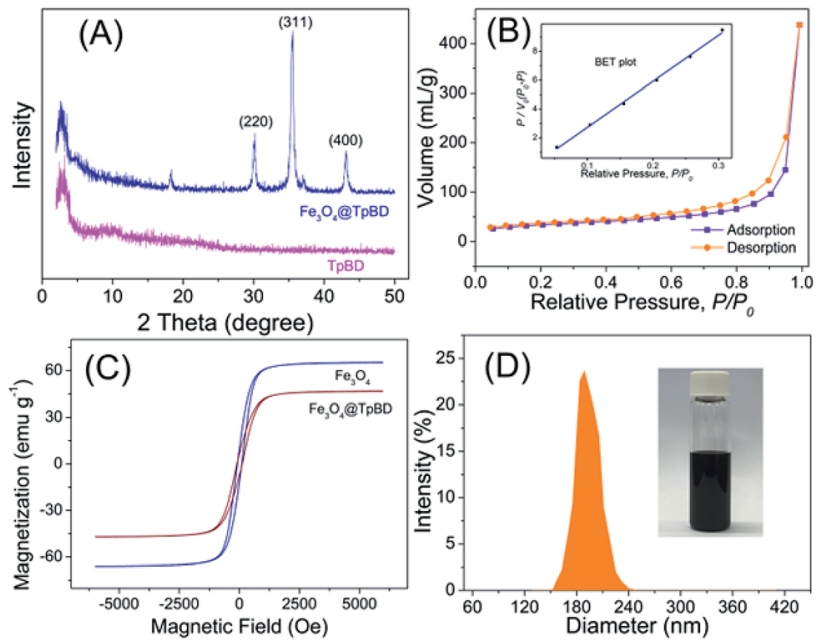

Fig. 2 Synthesis and characterization of magnetic $\mathrm{Fe}_{3} \mathrm{O}_{4} \mathrm{QT}$ TpBD SPE adsorbents: (A) XRD pattern of TpBD COFs; (B) $\mathrm{N}_{2}$ adsorptiondesorption isotherm of $\mathrm{Fe}_{3} \mathrm{O}_{4} @ \mathrm{CTpBD}$; (C) room-temperature magnetization curves of the as-prepared $\mathrm{Fe}_{3} \mathrm{O}_{4}$ and $\mathrm{Fe}_{3} \mathrm{O}_{4} \mathrm{QTpBD}$ materials; (D) DLS analysis of size distribution of $\mathrm{Fe}_{3} \mathrm{O}_{4} @ \mathrm{aTpBD}$ particles.

$\mathrm{Fe}_{3} \mathrm{O}_{4} @ \mathrm{TpBD}$ microspheres were measured at room temperature, and result was displayed in Fig. 2C. The magnetization saturation values of pure $\mathrm{Fe}_{3} \mathrm{O}_{4}$ and $\mathrm{Fe}_{3} \mathrm{O}_{4} @ \mathrm{TpBD}$ were as high as 63.48 and $46.12 \mathrm{emu}^{-1}$, respectively. These values were sufficiently high for fast magnetic-assisted separation by an external magnetic field. DLS analysis revealed that the size distribution of $\mathrm{Fe}_{3} \mathrm{O}_{4} @$ TpBD particles was $192 \pm 9 \mathrm{~nm}$ (Fig. 2D), larger than the results $(\sim 100 \mathrm{~nm})$ measured from TEM images, possibly due to the particle aggregation. The morphology of the as-synthesized samples was further identified by TEM and SEM analysis. SEM images in Fig. 3B showed that $\mathrm{Fe}_{3} \mathrm{O}_{4} @ \mathrm{TpBD}$ particles hold a relatively uniform and narrow size distribution. TEM characterization in Fig. 3C and D clearly demonstrated the initial smooth surface of $\mathrm{Fe}_{3} \mathrm{O}_{4}$ particles changed to relative rough surface after coating with TpBD shell. EDX mapping analysis of $\mathrm{Fe}_{3} \mathrm{O}_{4} @$ TpBD identified the presence of $\mathrm{Fe}$ (from $\mathrm{Fe}_{3} \mathrm{O}_{4}$ ), $\mathrm{O}$ (from $\mathrm{Fe}_{3} \mathrm{O}_{4}$ and COFs), and $\mathrm{N}$ (from COFs), further confirming the successful synthesis of $\mathrm{Fe}_{3} \mathrm{O}_{4} @ \mathrm{TpBD}$.

\subsection{Optimization of SPE conditions}

For the purpose of the achievement of rapid and efficient enrichment, the major experimental parameters influencing the performance of SPE such as eluent volume, eluent type and amount of adsorbent were studied. As indicated in Fig. 4A, eluent volume had a significant effect on the extraction recovery. The recoveries of ten sulfonamides residues increased with the increase of eluent volume from 1 to $5 \mathrm{~mL}$ and changed slightly when eluent volume was more than $5 \mathrm{~mL}$. In order to ensure sufficient extraction, $5 \mathrm{~mL}$ of eluent volume was considered to be more appropriate. Fig. 4B revealed that acetonitrile worked better as eluent. The effect of amount of $\mathrm{Fe}_{3} \mathrm{O}_{4} @ \mathrm{TpBD}$ in the range of $20-50 \mathrm{mg}$ on recovery was explored, and result indicated (Fig. 4C) that the amount of $\mathrm{Fe}_{3} \mathrm{O}_{4} @ T$ TpD had no significant effect on the extraction 

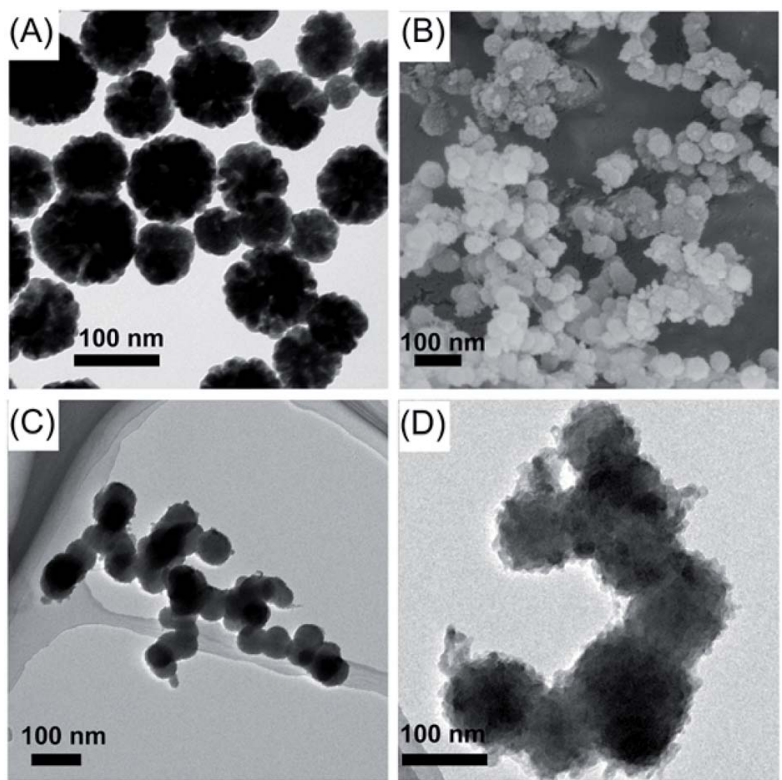

(E)
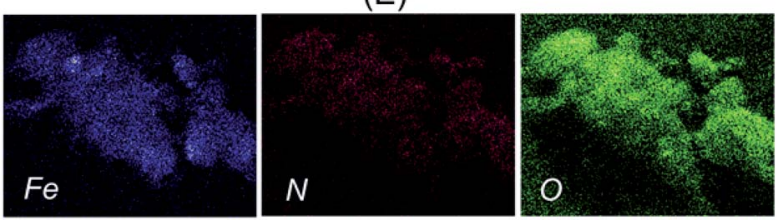

Fig. 3 Structural characterization of the fabricated $\mathrm{Fe}_{3} \mathrm{O}_{4} @ \mathrm{aTpBD}$ SPE adsorbents: (A) the representative TEM image of $\mathrm{Fe}_{3} \mathrm{O}_{4}$ magnetic particles; (B) the representative SEM image of $\mathrm{Fe}_{3} \mathrm{O}_{4} \mathrm{OTpBD}$; ( $\mathrm{C}$ and D) the representative TEM images of $\mathrm{Fe}_{3} \mathrm{O}_{4} \mathrm{QTpBD}$; (E) EDX mapping analysis of $\mathrm{Fe}_{3} \mathrm{O}_{4} \mathrm{QTpBD}$ in terms of $\mathrm{Fe}, \mathrm{N}$, and $\mathrm{O}$ elements. The scale bars all represent $100 \mathrm{~nm}$ for all images.

recovery. Fig. 4D suggested that HPLC separation mobile phase with the ratio of $22: 78$ (methanol/water) showed a good separation effect in a shorter period of time. Subsequently, HPLC separation chromatographs of ten sulfonamides residues with various concentrations using the above ration of mobile phase were conducted and results were shown in Fig. 5A. It was found that good separation effects could be achieved with various concentrations, demonstrating that this separation method was feasible and effective.

The extraction mechanism of magnetic COF to targets was investigated by adsorption kinetic and adsorption equilibrium assays. In the adsorption kinetic assay, $5 \mathrm{mg}$ of $\mathrm{Fe}_{3} \mathrm{O}_{4} @ \mathrm{TpBD}$ was separately added to respective $5 \mathrm{~mL}$ of ten target solution $\left(20 \mathrm{mg} \mathrm{L}^{-1}\right)$, and incubated at regular time intervals from $0 \mathrm{~min}$ to $30 \mathrm{~min}$ at room temperature. After magnetic separation, the supernatant was analyzed by UV-vis spectrophotometer at $270 \mathrm{~nm}$ to determine the target sulfonamides concentration. Results in Fig. 4E showed the adsorption capacity increased rapidly in the first $5 \mathrm{~min}$ and almost reached to balance after $10 \mathrm{~min}$, indicating a fast adsorption rate. In the adsorption equilibrium experiment, $5 \mathrm{mg}$ of $\mathrm{Fe}_{3} \mathrm{O}_{4} @ \mathrm{TpBD}$ was separately added to series of $5 \mathrm{~mL}$ target solution with the concentration in the range of $0-30 \mathrm{mg} \mathrm{L}^{-1}$. After $10 \mathrm{~min}$ incubation at room temperature, the supernatants were retrieved by magnetic
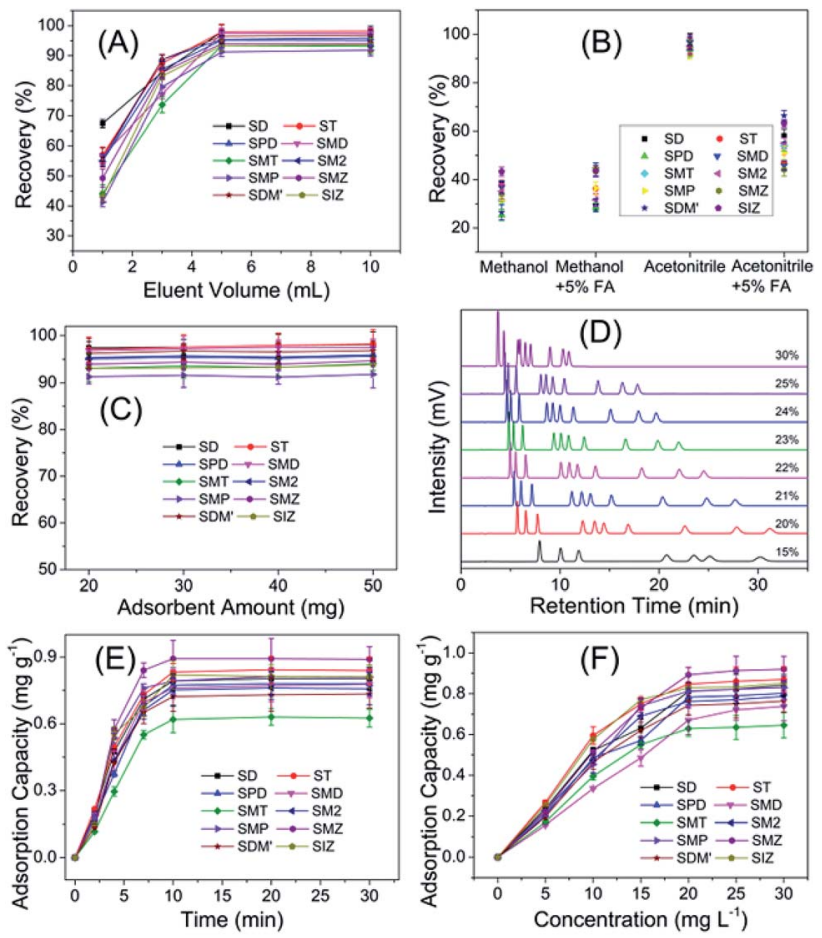

Fig. 4 Optimization of the magnetic TpBD-based SPE assay for HPLC determination of ten sulfonamides residues: (A) eluent solution volume of 1-10 mL; (B) eluent type; (C) amount of used adsorbents of 20-50 mg; (D) HPLC separation mobile phase (methanol + water) with the ratio of methanol in the range of $15-30 \%$; the tested sample concentration was all $5 \mu \mathrm{g} \mathrm{L}^{-1}$; (E) adsorption kinetic study; (F) adsorption equilibrium study.
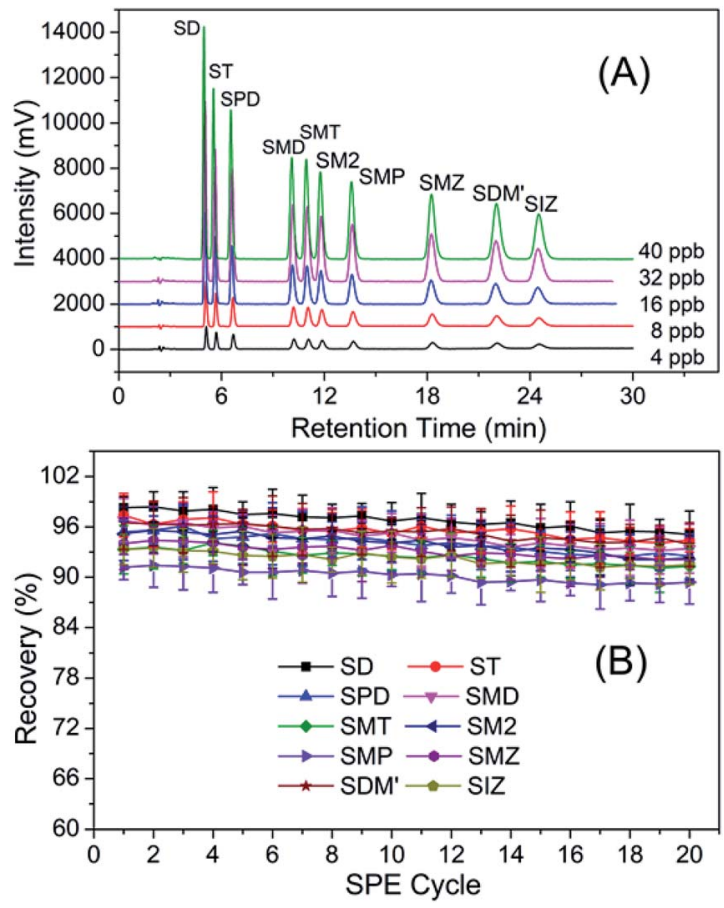

Fig. 5 (A) HPLC separation chromatographs of ten sulfonamides residues with various concentrations; (B) assessment of the reusability of the developed magnetic COFs adsorbents for SPE preconcentration and determination of target sulfonamides residues. 
Table 1 Analytical performance of the proposed SPE method for ten sulphonamides residues

\begin{tabular}{lllll}
\hline Analyte & $\begin{array}{l}\text { Liner range } \\
\left(\mu \mathrm{g} \mathrm{L}^{-1}\right)\end{array}$ & $R^{2}$ & $\begin{array}{l}\text { LOD }(\mu \mathrm{g} \\
\left.\mathrm{L}^{-1}\right)\end{array}$ & $\begin{array}{l}\mathrm{RSD}(\%, \\
n=11)\end{array}$ \\
\hline SD & $1-20$ & 0.9990 & 0.28 & 1.8 \\
ST & $1-20$ & 0.9990 & 0.33 & 2.8 \\
SPD & $1-20$ & 0.9991 & 0.29 & 1.2 \\
SMD & $2-40$ & 0.9992 & 0.54 & 2.6 \\
SMT & $2-40$ & 0.9990 & 0.67 & 2.4 \\
SM2 & $2-40$ & 0.9988 & 0.72 & 2.3 \\
SMP & $2-40$ & 0.9993 & 0.69 & 2.6 \\
SMZ & $4-80$ & 0.9990 & 1.21 & 3.1 \\
SDM & $4-80$ & 0.9990 & 1.45 & 3.3 \\
SIZ & $4-80$ & 0.9990 & 1.19 & 1.9
\end{tabular}

separation and analyzed by UV-vis spectrophotometer at $270 \mathrm{~nm}$ to determine the target sulfonamides concentration. Results in Fig. 4F showed the adsorption capacity increased with the incubating concentration, and reached nearly to the top at $20 \mathrm{mg} \mathrm{L}^{-1}$. The adsorption processes were interpreted with Langmuir and Freundlich isotherm models, of which results fitted better with Freundlich model, indicating the adsorption tend to be a multiple process rather than monolayer adsorption.

As comparison, amino-functionalized $\mathrm{Fe}_{3} \mathrm{O}_{4}$ microsphere without surface coating of TpBD COF was employed as adsorbents for preconcentration of target sulfonamides under the same experiment conditions as $\mathrm{Fe}_{3} \mathrm{O}_{4} @ \mathrm{TpBD}$. The non-coated $\mathrm{Fe}_{3} \mathrm{O}_{4}$ microsphere demonstrated poor adsorption performance to the ten analytes with the adsorption capacity in the range of $0.1632-0.2374 \mathrm{mg} \mathrm{g}{ }^{-1}$, relative to $\mathrm{Fe}_{3} \mathrm{O}_{4} @ \mathrm{TpBD}$ (0.6296$\left.0.8472 \mathrm{mg} \mathrm{g}^{-1}\right)$ at incubating concentration of $20 \mathrm{mg} \mathrm{L}^{-1}$.

\subsection{Method validation}

Based on above results, calibration curves were constructed for the determination of ten sulfonamides residues according to the general procedure. The equations of linear regression, correlation coefficients $\left(R^{2}\right)$ and limit of detection (LOD) were obtained from the calibration curves. The relative standard deviation (RSD) values were obtained by eleven determinations. As indicated in Table 1, the $R^{2}$ values of all the analytes were greater than 0.99 and the LOD of all the analytes were lower than $1.5 \mathrm{ppb}$. These results indicated that the proposed SPE method had great potential for highly efficient determination of sulfonamides residues.

\subsection{Analytical performance in real samples}

To evaluate the applicability of the presented magnetic $\mathrm{Fe}_{3}$ $\mathrm{O}_{4} @$ TpBD-based SPE assay, it was employed for the determination of targets in real sample, including pork, beef and chicken (obtained from Food and Drug Administration of Shandong, China, sulfonamide-positive samples with number of RL2018160-RL2018165). From the obtained results displayed in Table 2, it could be found that only three targets (SD, SM2, and SMZ) were detected in the real samples, of which results was allowable referring to the international maximum residue limits (MRLs) of $100 \mathrm{ppb}$ for sulfonamides in food of animal origin. ${ }^{39}$ The recoveries of the spiked samples were in the range of $82-92 \%$ for pork samples, $85-94 \%$ for beef samples, and $83-$ $93 \%$ for chicken samples, respectively. The above results demonstrated that the developed magnetic COF-SPE method possessed excellent applicability and feasibility for the detection of sulfonamides residues in complex food samples.

Table 2 Analytical results of real samples using the magnetic COFs-SPE method (mean \pm SD, $n=3$; ND: not detected)

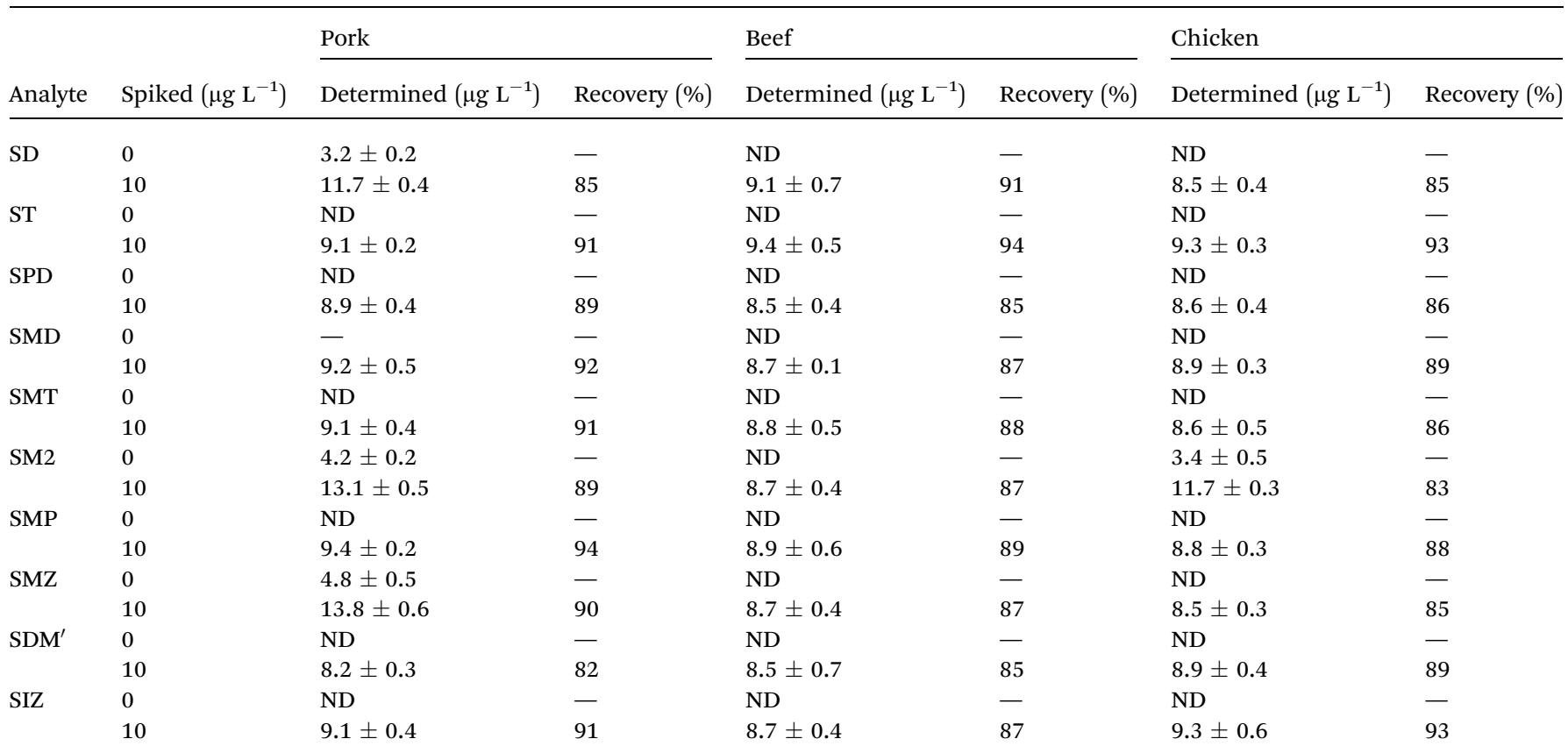


Table 3 Comparison of analytical performance of the proposed SPE method with previously-reported methods in terms of adsorbents, sensitivity, linear range and recovery

\begin{tabular}{|c|c|c|c|c|c|}
\hline Adsorbents & Limit of detection $\left(\mu \mathrm{g} \mathrm{L}^{-1}\right)$ & Enrichment factor & Linear range $\left(\mu \mathrm{g} \mathrm{L}^{-1}\right)$ & Recovery (\%) & Reference \\
\hline GO & $1.04-1.50$ & 2 & $10-10000$ & $62-109$ & 7 \\
\hline $\mathrm{Fe}_{3} \mathrm{O}_{4} @ \mathrm{MOFs}$ & $1.73-5.23$ & 10 & $3.97-1000$ & $76-103$ & 9 \\
\hline $\mathrm{GO} / \mathrm{CNTs} / \mathrm{Fe}_{3} \mathrm{O}_{4}$ & $0.35-1.32$ & $24.72-30.15$ & $5-500$ & $88-106$ & 38 \\
\hline $\mathrm{Fe}_{3} \mathrm{O}_{4} @ \mathrm{COFs}$ & $0.28-1.45$ & 100 & $1-80$ & $82-94$ & This work \\
\hline
\end{tabular}

\subsection{Reusability and comparison}

In general, the reusability of adsorbent is one of the most important indicators in the commercial application. In this study, therefore, the reusability of $\mathrm{Fe}_{3} \mathrm{O}_{4} @$ TpBD was evaluated through adsorption and elution cycles. As shown in Fig. 5B, the recoveries of the targets (namely ten sulfonamides residues) were all above $85 \%$ after 20 adsorption-elution cycles, indicating that $\mathrm{Fe}_{3} \mathrm{O}_{4} @$ @TBD had great reusability and could be an alternative adsorbent for the detection of sulfonamides residues.

To clearly illustrate the advantages of the developed magnetic COF-SPE method, the comparisons of the proposed method with the previously reported methods for sulfonamides residues detection were summarized in Table 3. It was found that the LOD obtained via the present method was lower than these obtained via other methods, and the sample analysis recovery performance was better as well. Therefore, $\mathrm{Fe}_{3} \mathrm{O}_{4}$ @TpBD could be considered as an efficient absorbent for sulfonamides residues analysis.

\section{Conclusions}

From the above, core-shell structured magnetic COFs have been well demonstrated as ideal solid phase extraction adsorbents for complex food sample analysis. In favor of combination of magnetic separation and effective preconcentration, the proposed magnetic COF-SPE method gave rapid detection performance, high sensitivity and good reusability to target analytes. It was believed that the new emerging porous nano/ micro-materials, like COFs, metal organic networks, or hybrid structures, would play more and more important roles of functional materials in food-safety inspection, especially for highly efficient determination of targets against complicated food sample matrix.

\section{Conflicts of interest}

There are no conflicts to declare.

\section{Acknowledgements}

This work was financially supported by National Key R\&D Program of China (No. 2018YFC1602401), National Natural Science Foundation of China (No. 21806083), and the Fundamental Research Funds for the Central Universities, Nankai University (No. 63191429).

\section{Notes and references}

1 X.-L. Chen, L.-F. Ai, Y.-Q. Cao, Q.-X. Nian, Y.-Q. Jia, Y.-L. Hao, M.-M. Wang and X.-S. Wang, Food Anal. Method., 2019, 12, 271-281.

2 S. Hu, M. Zhao, Y. Xi, Q. Mao, X. Zhou, D. Chen and P. Yan, J. Agric. Food Chem., 2017, 65, 1984-1991.

3 I. Guillen, L. Guardiola, L. Almela, E. Nunez-Delicado and J. A. Gabaldon, Food Anal. Method., 2017, 10, 1430-1441.

4 X. Fu, H. Liang, B. Xia, C. Huang, B. Ji and Y. Zhou, J. Agric. Food Chem., 2017, 65, 8256-8263.

5 J. X. He, S. Wang, G. Z. Fang, H. P. Zhu and Y. Zhang, J. Agric. Food Chem., 2008, 56, 2919-2925.

6 G. Z. Fang, J. X. He and S. Wang, J. Chromatogr. A, 2006, 1127, 12-17.

7 M. Qi, C. Tu, Z. Li, W. Wang, J. Chen and A.-J. Wang, Food Anal. Method., 2018, 11, 2885-2896.

8 T. G. Chatzimitakos and C. D. Stalikas, J. Chromatogr. A, 2018, 1554, 28-36.

9 L. Xia, L. Liu, X. Lv, F. Qu, G. Li and J. You, J. Chromatogr. A, 2017, 1500, 24-31.

10 C.-H. Wen, S.-L. Lin and M.-R. Fuh, Talanta, 2017, 164, 8591.

11 S. G. Dmitrienko, E. V. Kochuk, V. V. Apyari, V. V. Tolmacheva and Y. A. Zolotov, Anal. Chim. Acta, 2014, 850, 6-25.

12 H. Peng, N. Zhang, M. He, B. Chen and B. Hu, Talanta, 2015, 131, 266-272.

13 S. Chen, S. Zhu, Y. He and D. Lu, Food Chem., 2014, 150, 254259.

14 T.-T. Shih, C.-H. Lin, I. H. Hsu, J.-Y. Chen and Y.-C. Sun, Anal. Chem., 2013, 85, 10091-10098.

15 L. Zhao, S. Zhong, K. Fang, Z. Qian and J. Chen, J. Hazard. Mater., 2012, 239, 206-212.

16 J. Wang, X. Ma, G. Fang, M. Pan, X. Ye and S. Wang, J. Hazard. Mater., 2011, 186, 1985-1992.

17 N. Li, H.-L. Jiang, X. Wang, X. Wang, G. Xu, B. Zhang, L. Wang, R.-S. Zhao and J.-M. Lin, TrAC, Trends Anal. Chem., 2018, 102, 60-74.

18 M. Hemmati, M. Rajabi and A. Asghari, Microchim. Acta, 2018, 185, 160.

19 I. Vasconcelos and C. Fernandes, TrAC, Trends Anal. Chem., 2017, 89, 41-52.

20 F. Maya, C. Palomino Cabello, R. M. Frizzarin, J. M. Estela, G. Turnes Palomino and V. Cerda, TrAC, Trends Anal. Chem., 2017, 90, 142-152. 
21 L. Xie, J. Guo, Y. Zhang and S. Shi, J. Agric. Food Chem., 2014, 62, 8221-8228.

22 F. Wei, Q. Zhao, X. Lv, X.-Y. Dong, Y.-Q. Feng and H. Chen, J. Agric. Food Chem., 2013, 61, 76-83.

23 L.-S. Qing, Y. Xue, Y.-M. Liu, J. Liang, J. Xie and X. Liao, J. Agric. Food Chem., 2013, 61, 8072-8078.

24 Q. Zhao, F. Wei, Y.-B. Luo, J. Ding, N. Xiao and Y.-Q. Feng, J. Agric. Food Chem., 2011, 59, 12794-12800.

25 W. A. W. Ibrahim, H. R. Nodeh, H. Y. Aboul-Enein and M. M. Sanagi, Crit. Rev. Anal. Chem., 2015, 45, 270-287.

26 C. Herrero-Latorre, J. Barciela-Garcia, S. Garcia-Martin, R. M. Pena-Crecente and J. Otarola-Jimenez, Anal. Chim. Acta, 2015, 892, 10-26.

27 D. Huang, C. Deng and X. Zhang, Anal. Methods, 2014, 6, 7130-7141.

28 F. L. Zhao, H. M. Liu, S. D. R. Mathe, A. J. Dong and J. H. Zhang, Nanomaterials, 2018, 8, 15.

29 J.-Y. Ren, X.-L. Wang, X.-L. Li, M.-L. Wang, R.-S. Zhao and J.-M. Lin, Anal. Bioanal. Chem., 2018, 410, 1657-1665.

30 H. L. Qian, C. X. Yang, W. L. Wang, C. Yang and X. P. Yan, J. Chromatogr. A, 2018, 1542, 1-18.
31 W.-K. Meng, L. Liu, X. Wang, R.-S. Zhao, M.-L. Wang and J.-M. Lin, Anal. Chim. Acta, 2018, 1015, 27-34.

32 S. He, T. Zeng, S. Wang, H. Niu and Y. Cai, ACS Appl. Mater. Interfaces, 2017, 9, 2959-2965.

33 J. L. Segura, M. J. Mancheno and F. Zamora, Chem. Soc. Rev., 2016, 45, 5635-5671.

34 H.-L. Qian, C.-X. Yang and X.-P. Yan, Nat. Commun., 2016, 7, 12104.

35 C. Mongin, S. Garakyaraghi, N. Razgoniaeva, M. Zamkov and F. N. Castellano, Science, 2016, 351, 369-372.

36 N. Huang, P. Wang and D. L. Jiang, Nat. Rev. Mater., 2016, 1, 16068.

37 Z. Li, Y. Li, M. Qi, S. Zhong, W. Wang, A.-J. Wang and J. Chen, J. Sep. Sci., 2016, 39, 3818-3826.

38 Y. Feng, X. Hu, F. Zhao and B. Zeng, J. Sep. Sci., 2019, 42, 1058-1066.

39 J. M. K. J. K. Premarathne, D. A. Satharasinghe, A. R. C. Gunasena, D. M. S. Munasinghe and P. Abeynayake, Food Control, 2017, 72, 276-282. 